УДК 629.424.4

\title{
ПОБУДОВА МОДЕЛІ ЕЛЕКТРОПЕРЕДАЧІ ДИЗЕЛЬ-ПОЇЗДА ДЕЛ-О2 ДЛЯ ДОСЛІДЖЕННЯ РЕЖИМІВ ГАЛЬМУВАННЯ
}

\author{
В.С. Дяченко, асп. О.О. Шкурпела, канд. техн. наук С.І. Яцько
}

ПОСТРОЕНИЕ МОДЕЛИ ЭЛЕКТРОПЕРЕДАЧИ ДИЗЕЛЬ-ПОЕЗДА ДЕЛ-02 ДЛЯ ИССЛЕДОВАНИЯ РЕЖИМОВ ТОРМОЖЕНИЯ

\author{
В.С. Дьяченко, асп. А.А. Шкурпела, канд. техн. наук С.И. Яцко
}

\section{BUILDING A MODEL TRANSMISSION TRAINS DEL-02 FOR RESEARCH BRAKING MODE}

\begin{abstract}
V.S. Dyachenko, postgraduate A. Shkurpela, cand. of techn. sciences S. Yatsko
Розглянуто актуальне питання визначення основних підходів до розроблення математичної моделі тягової електропередачі дизель-поїзда ДЕЛ-02 для проведення дослідження як штатних, так $і$ нештатних режимів ї̈ роботи з метою покращення технічних та експлуатачійних характеристик дизель-поїзда.
\end{abstract}

Ключові слова: електропередача, дизель-поӥзд, асинхронний тяговий електродвигун, математична модель, холостий хід, коротке замикання.

Рассмотрен актуальный вопрос определения основных подходов $к$ разработке математической модели тяговой электропередачи дизель-поезда ДЕЛ-02 для проведения исследования как итатных, так и нештатных режимов ее работы с иелью улучшения технических и эксплуатационных характеристик дизель-поезда.

Ключевые слова: электропередача, дизель-поезд, асинхронный тяговый электродвигатель, математическая модель, холостой ход, короткое замыкание.

In the article a question is examined on determination of basic approaches on development of mathematical model of hauling electricity transmission of the traction power diesel train DEL-02 for the leadthrough of research both regular and nonpermanent, its office hours with the purpose of improvement of technical and operating descriptions a diesel is trains.

Keywords: electricity Trains, asynchronous traction motor mathematical model, idle progresses, short-circuiting.

Вступ, постановка задачі, аналіз останніх досліджень та публікацій. Дизель-поїзд ДЕЛ-02 вітчизняного виробництва обладнаний тяговим приводом змінного струму 3 асинхронними тяговими двигунами АД906У1, перетворювачами частоти із загальною ланкою поруійного мікропроцесорною системою керування та силовим модулем (дизель-генератор) "РошегРаск" виробництва фірми MTU (Німеччина) (рис. 1). Дизель-поїзд обладнаний реостатним гальмуванням.
Незважаючи на широке використання на різних рухомих одиницях тягового привода системи «інвертор напруги асинхронний двигун», продовжуються інтенсивні дослідження щодо поліпшення його як технічних, так і експлуатаційних характеристик [1-4]. При цьому широко використовуються методи математичного моделювання, що дає змогу проводити дослідження складної системи, якою і є тягова електропередача дизель-поїзда ДЕЛ-02. 


\section{Електричний транспорт}

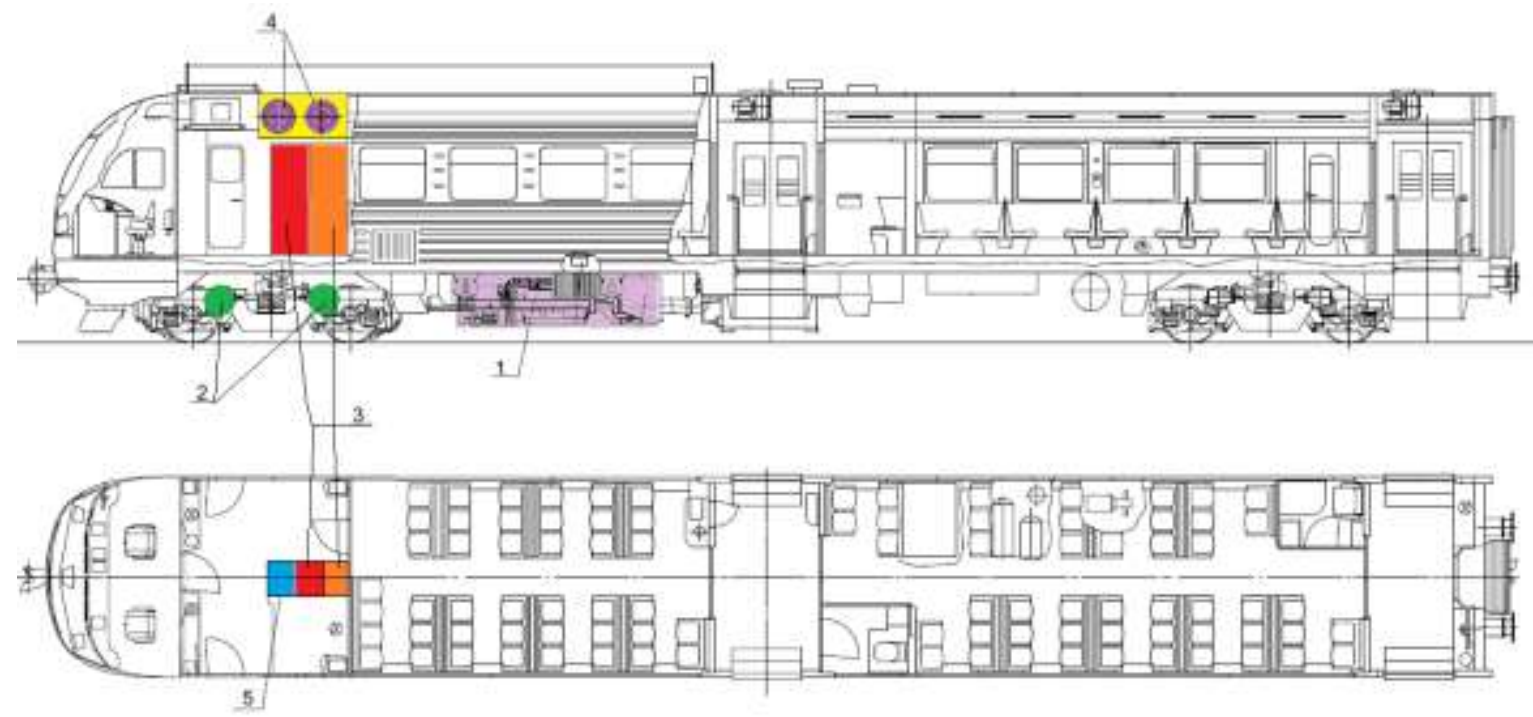

Рис. 1. Розміщення елементів модуля тягової електропередачі дизель-поїзда ДЕЛ-02:

1 - силовий модуль "PowerPack"; 2 - асинхронні тягові двигуни; 3 - тягові перетворювачі частоти; 4 - мотор-вентилятори охолодження гальмівних резисторів; 5 - перетворювач власних потреб

Мета роботи полягає у розробленні математичної моделі тягової електропередачі дизель-поїзда ДЕЛ-02 для проведення дослідження як штатних, так і нештатних режимів іiі роботи.

\section{Матеріали та результати} досліджень. На рис. 2 показано реалізовану в програмному середовищі MATLAB 7 математичну модель модуля тягової електропередачі (ТЕП) дизель-поїзда ДЕЛ-02. Прототипом даної моделі $\epsilon$ модель, яка наведена в роботі [4].

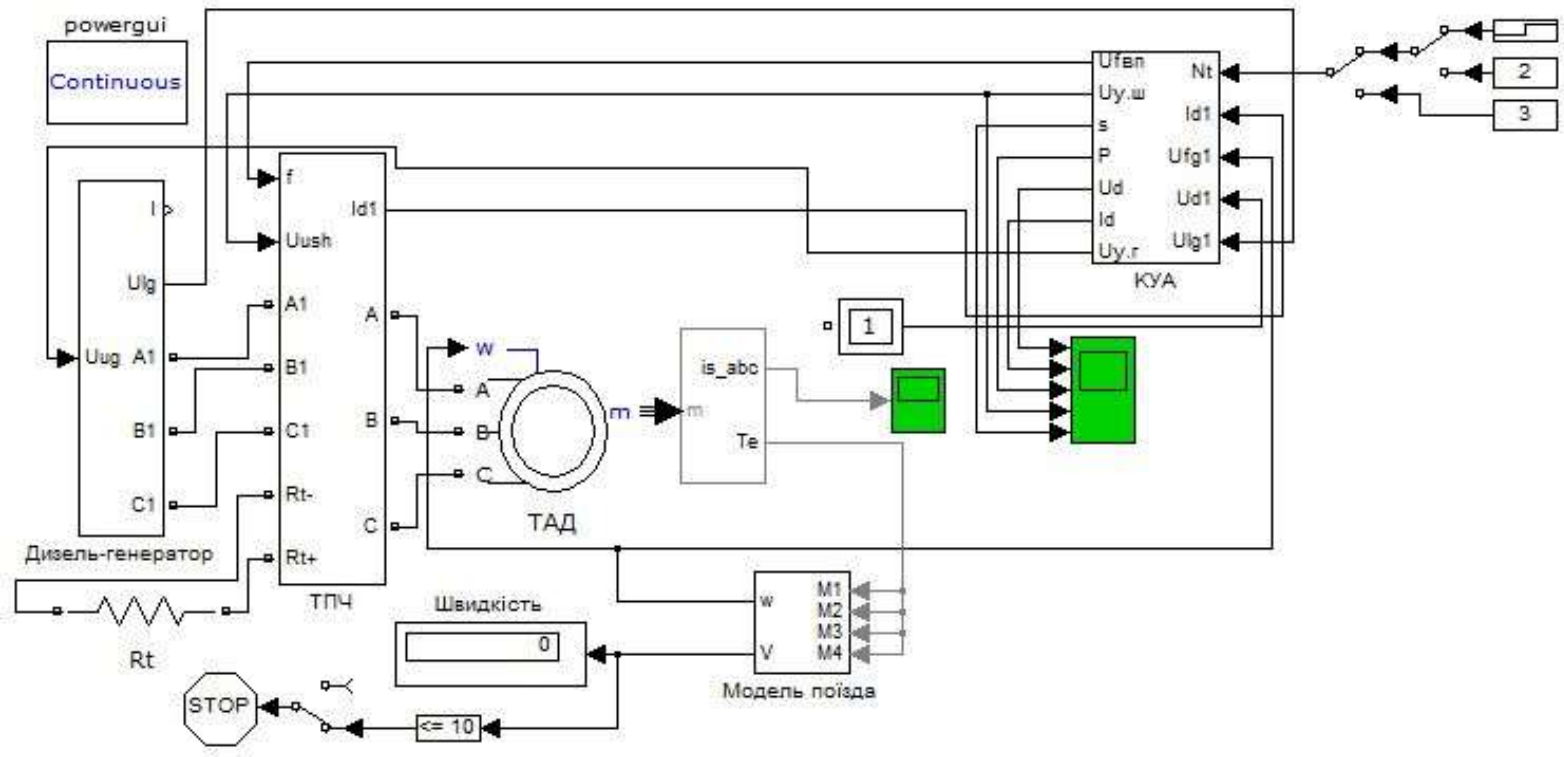

Рис. 2. Модель електропередачі дизель поїзда ДЕЛ-02 
Модель системи керування модуля тягової електропередачі в режимі електродинамічного гальмування залишилася незмінною у порівнянні 3 прототипом та містить:

- блок регулятора напруги тягового синхронного генератора;

- блок обчислення фазного струму тягового асинхронного двигуна;

- блоки регуляторів частоти та напруги автономного інвертора напруги (AIH).

Тривалість циклу роботи програми системи керування складає 2 мс. Система керування транзисторного перетворювача частоти (ТПЧ) згідно із сигналами $\mathrm{U}_{\mathrm{yш}}$ (глибини модуляції) та $\mathrm{U}_{\mathrm{fвп}}$ (частоти струму) формує керуючі імпульси трифазного мостового інвертора, реалізованого на базі транзисторів типу IGBT зі зворотними діодами.

Особливістю моделі $є$ попередня підготовка ланки постійного струму, по завершенню якої формується сигнал початку гальмування.

В розглянутій моделі систему тягової електропередачі, що містить АД та певну механічну частину 3 пружними зв'язками для дослідження перехідних процесів, подано у вигляді двомасової електромеханічної системи.

Щодо математичної моделі зчеплення колісних пар з рейкою, то поточне значення коефіцієнта зчеплення визначається як

$$
\Psi j=R j \cdot \Psi o j \cdot \Psi j \partial,
$$

де зчеплення $j$-ї колісної пари;

$R j$ - коефіцієнт, який враховує зміну умов зчеплення $j$-ї колісної пари;

$\Psi j \partial-$ значення коефіцієнта зчеплення в часткових одиницях $j$-ї колісної пари, визначеної за універсальною характеристикою зчеплення $\Psi^{\text {д }}=f(u, V)$, де $u$ - величина проковзування колісної пари; $V$ - швидкість руху дизель-поїзда.

Залежність коефіцієнта зчеплення в часткових одиницях від величини проковзування (в часткових одиницях, де за базову величину беруть швидкість руху дизель-поїзда) 3 допустимою точністю апроксимована виразом (рис. 3)

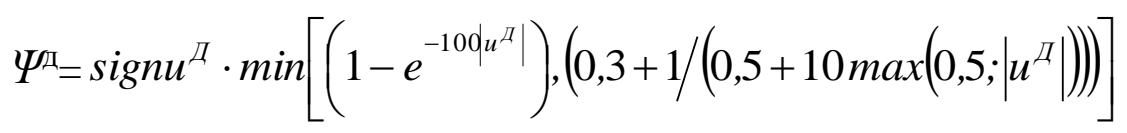

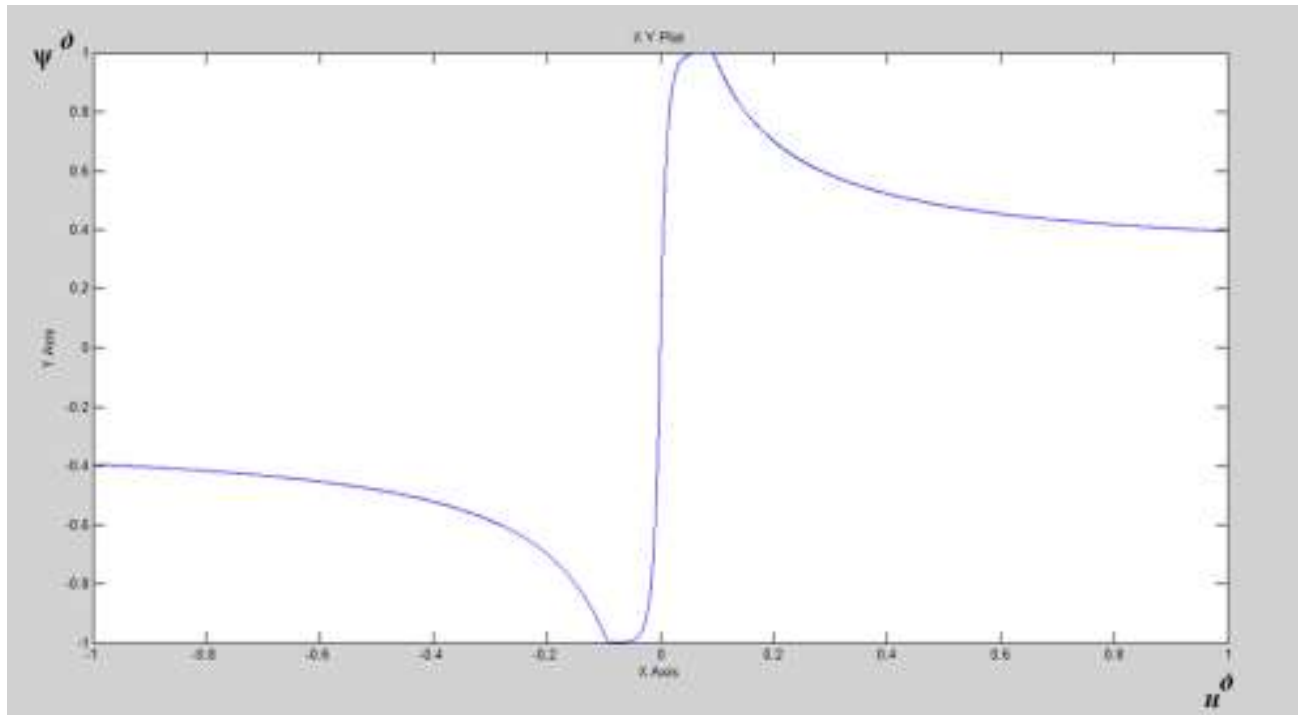

Рис. 3. Графік залежності $\Psi^{\text {म }}\left(\mathrm{u}^{\text {म }}\right)$ 
Щодо величини проковзування $j$-ї колісної пари відносно рейки, то вона визначається шляхом розв'язування диференціального рівняння

$$
d u j / d t=(F j-P j \cdot \psi j) / J j,
$$

де $F j$ - тягове (гальмівне $B j$ ) зусилля на ободі колісної пари, створюване тяговим електричним двигуном;

$P j$ - вага локомотива, що припадає на $j$-у колісну пару;

$\psi j$ - реалізований коефіцієнт зчеплення;

$J j-$ момент інерції, приведений до осі $j$-ї колісної пари.

У свою чергу швидкість руху дизельпоїзда визначається розв'язанням такого диференціального рівняння

$$
d V / d t=(\Sigma P j \cdot \psi j+\Sigma W) / \Sigma M,
$$

де $V$ - швидкість руху дизель - поїзда;

$\Sigma P j \cdot \psi j$ - тягове (гальмівне) зусилля;

$\Sigma W$ - опір руху поїзда;

$\Sigma M$ - сумарна маса поїзда.

Наведена математична модель дає змогу дослідити роботу ТЕП в штатних та нештатних режимах, в тому числі при наявності відхилень параметрів основного обладнання. Адекватність розробленої моделі реальній тяговій електропередачі була підтверджена шляхом аналізу результатів моделювання та осцилограм, отриманих в умовах рядової експлуатації.

Як ілюстрація характеру процесу електродинамічного гальмування, на рис. 4 наведено фрагмент процесу гальмування дизель-поїзда зі швидкістю 50 км/год, отриманий за допомогою математичної моделі.
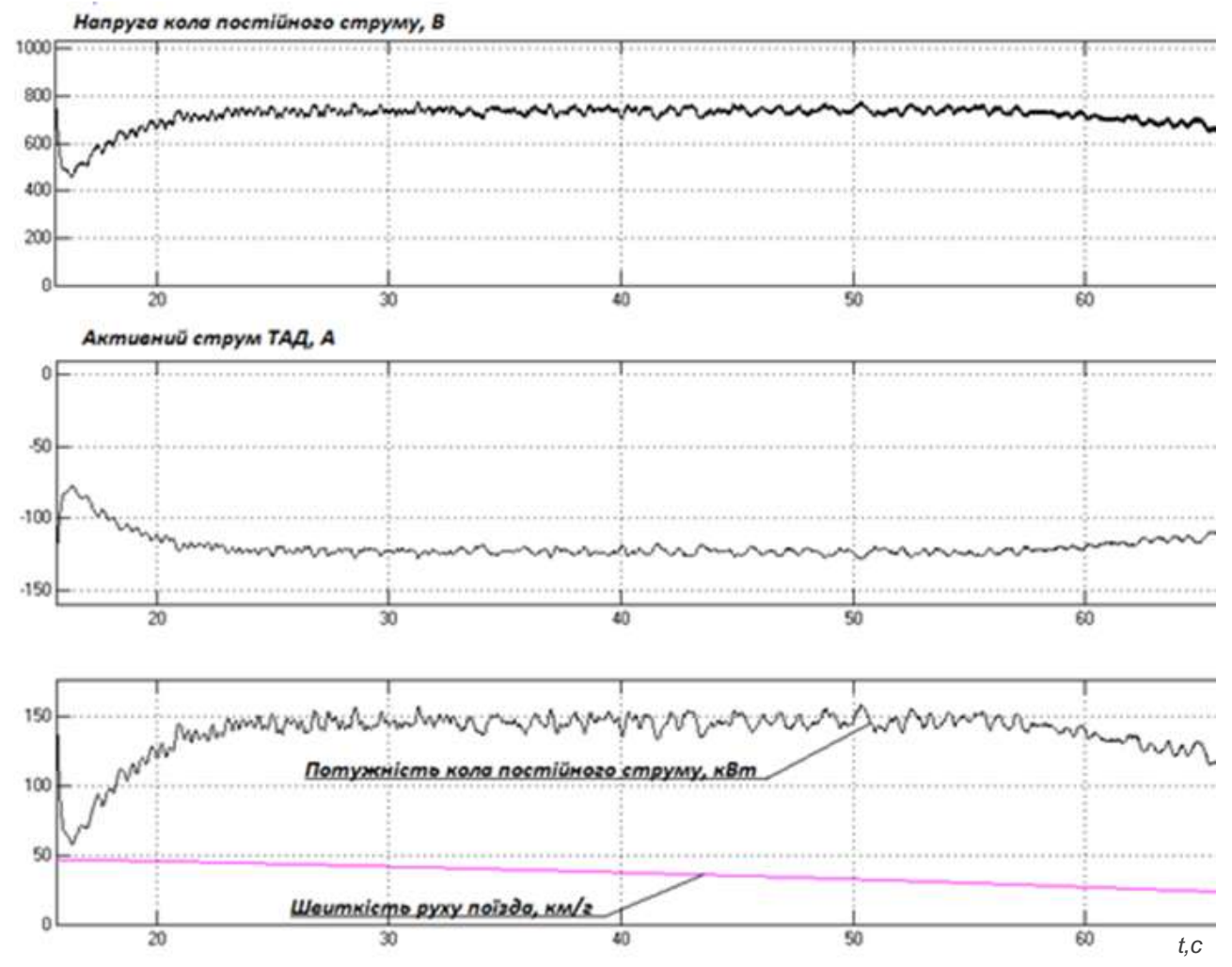

Рис. 4. Результати моделювання режиму гальмування

Висновки. Отримана математична модель модуля ТЕП дизель-поїзда ДЕЛ-02 в режимі електродинамічного гальмування адекватна об'єкту дослідження та дає можливість проводити дослідження штатних та нештатних режимів роботи 
ТЕП. Дана модель може бути використана для уточнення алгоритму системи регулювання 3 метою забезпечення необхідних динамічних характеристик системи тягової електропередачі в ході всього циклу гальмування.

\section{Список використаних джерел}

1. Андрієнко, П.Д. Порівняльний аналіз регуляторів системи керування струмом тягового частотно - керованого електропривода дизель-поїзда ДЕЛ-02 [Текст] / П.Д. Андрієнко, Д.О. Кулагін, О.С. Качур // Електромашинобудування та електрообладнання. - 2010. - № 75. - С. 32-36.

2. Носков, В.І. Створення тягового електроприводу моторвагонних поїздів на базі сучасних інформаційних технологій [Текст]: автореф. дис. ... д-ра техн. наук / Носков Валентин Іванович; НТУ «ХПІ». - Харків, 2009. - 37 с.

3. Кулагін, Д.О. Підвищення ефективності роботи тягової електропередачі дизельпоїздів ДЕЛ-02 [Текст]: автореф. дис. ... канд. техн. наук: 05.22.07 / Кулагін Дмитро Олександрович; ДП "Держ. н.-д. центр залізн. трансп. України". - К., 2011. - 18 с.

4. Яровий, Г.І. Побудова математичної моделі електропередачі дизель-поїзда ДЕЛ-02 [Текст] / Г.І. Яровий, Д.В. Ніконенко, О.О. Шкурпела, І.О. Тукалов // Зб. наук. праць. Харків: УкрДАЗТ, 2013. - Вип. 136. - С. 152-162.

Рецензент д-р техн. наук, професор А.П. Фалендиш

Дяченко Володимир Сергійович, слухач ІППК, гр. МЗ-ЕТ-Б-11.

Яцько Сергій Іванович, канд. техн. наук, доцент кафедри автоматизованих систем електричного транспорту.

Шкурпела Олександр Олександрович, аспірант.

Dyachenko V.S., Shkurpela A., postgraduate, Yatsko S., cand. of techn. sciences. 